Gut, 1964, 5, 573

\title{
Effect of acid in the duodenum on histamine-stimulated gastric secretion in man
}

\author{
D. JOHNSTON AND H. L. DUTHIE
}

From the University Department of Surgery, Leeds

\begin{abstract}
EDITORIAL SYNOPSIS In normal subjects, the secretion of gastric juice in response to a constant intravenous infusion of histamine in near maximal dosage diminished when $\mathrm{N} / 10$ hydrochloric acid was infused into the proximal duodenum. In patients with duodenal ulcer the secretion of gastric juice was inhibited when submaximal doses of histamine were used but to a lesser degree than in the normal subjects. When the histamine stimulus was nearly maximal, no inhibition was found in the patients with duodenal ulcer.
\end{abstract}

The most important inhibitor of gastric secretion is the gastric acid itself, acting on the gastric antrum and duodenum. When these sites are excluded from gastrointestinal continuity, gastric secretion in the dog is greatly increased (Uvnäs, Andersson, Elwin, and Malm, 1956). The relative importance of each site is not clearly defined. Many authors have demonstrated inhibition from the antrum in animals (Woodward, Lyon, Landor and Dragstedt, 1954; Longhi, Greenlee, Bravo, Guerrero, and Dragstedt, 1957; Shapira and State, 1961), and Gillespie (1959) showed diminution in acid gastric secretion when acid was placed in the antrum in man. Unfortunately the acid also passed into the duodenum so that inhibition could have been in part from the duodenum.

Many workers have also observed inhibition of gastric secretion when acid is placed in the duodenum in dogs (Sokolov, 1904; Day and Webster, 1935; Pincus, Thomas, and Rehfuss, 1942; Code and Watkinson, 1955; Jones and Harkins, 1959; Andersson, 1960a and b; Andersson and Uvnäs, 1961). However, in man the evidence is not so uniform. Inhibition of acid gastric secretion by acid in the duodenum was shown by Griffiths (1936) and by Shay, Gershon-Cohen, and Fels (1942). No inhibition was found by Stevens, Segal, and Scott (1939). Yet a third result was obtained when Ivy and McIlvain (1923) showed an increase in gastric secretion in response to acid in the duodenum in man. Because of the limitations imposed by the use of fractional gastric analysis, little or no information is available in these papers about total acid output, the $p \mathrm{H}$ attained in the duodenum, the precise part of the duodenum exposed to acid, and the amount of reflux of duodenal contents into the stomach. We have attempted to supply these data in studying the effect of acid in the duodenum on histaminestimulated gastric secretion in normal subjects and in patients with duodenal ulcer.

\section{MATERIAL AND METHODS}

Twenty-six normal subjects, aged 19 to 42 , and 21 patients with duodenal ulcer, aged 25 to 62 , were tested.

To summarize the method, gastric secretion was stimulated by a continuous infusion of histamine. The dose was sometimes maximal, sometimes submaximal. When a steady level of secretion was established N/10 hydrochloric acid was infused into the proximal part of the duodenum.

TUBES After the subject had fasted overnight, two tubes were passed transnasally into the stomach. One tube was a 12 Fr. gauge gastric tube made of polyethylene with a radio-opaque tip: the other was a double-lumen 'duodenal' tube with a metal stylet to give additional stiffness. Under radiographic control the gastric tube was placed with its suction holes in the most dependent part of the stomach and the duodenal tube was advanced into the second part of the duodenum. In normal subjects this was achieved easily, in most cases in a few minutes; in patients with duodenal ulcer, more difficulty was encountered, with a failure rate of about one third.

STIMULUS Histamine acid phosphate in a dose of 0.025 to 0.4 micrograms per kilogram body weight per minute was given by intravenous infusion to stimulate gastric secretion in all tests. No antihistaminic was required to protect against systemic side effects at doses under $0.2 \mu \mathrm{g}$. per $\mathrm{kg}$. per minute. At the higher dose levels, $50 \mathrm{mg}$. Anthisan was given slowly intravenously at the start of the test. The appropriate dose of histamine acid 
phosphate was diluted in sterile $0.9 \%$ saline and infused at a rate of $30 \mathrm{ml}$. per $10 \mathrm{~min}$. using a paediatric giving set. In patients with duodenal ulcer, two groups of tests were done: group I received a dose of $0.4 \mu \mathrm{g}$. per $\mathrm{kg}$. per min. and group II one of $0.2 \mu \mathrm{g}$. per $\mathrm{kg}$. per min. or less. In the normal subjects doses of $0.05,0 \cdot 1$, or $0.2 \mu \mathrm{g}$. per $\mathrm{kg}$. per min. were given.

INHIBITOR After one hour, or when a plateau of gastric secretion had been established, N/10 hydrochloric acid was infused into the duodenum via the inner lumen of the double-lumen tube. Polyethylene glycol, $0.5 \%$, was added to the hydrochloric acid as a marker in order to detect any reflux into the stomach. During each 15minute period, 100 to $150 \mathrm{ml}$. of acid was run in. The infusion usually lasted 45 to 60 minutes. Physiological saline was infused in some cases as a control. The suction applied to the duodenal tube (vide infra) recovered as much as $200 \mathrm{ml}$. of duodenal content per 15 minutes, so providing a perfusion of the proximal duodenum (Fig. 1).

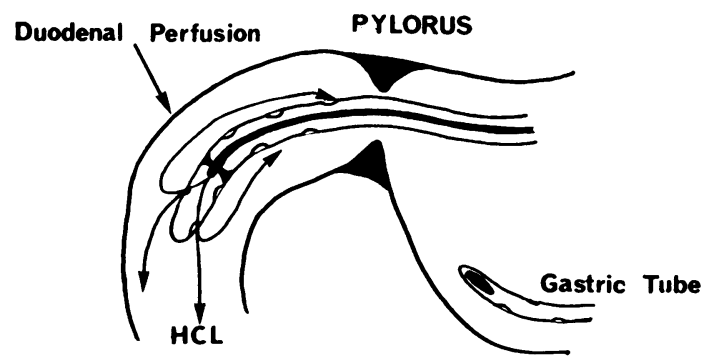

FIG. 1. Diagram showing the double-lumen duodenal tube in situ and the circulation of acid in the duodenum.

SPECIMENS Continuous suction was exerted on both the gastric and the duodenal tubes for three hours. The gastric suction at $10 \mathrm{~cm}$. $\mathrm{Hg}$ was twice as powerful as the duodenal suction. This difference, together with careful siting of the gastric tube, minimized losses of gastric juice through the pylorus. The lumen of the gastric tube was kept patent by frequent injection of small amounts of air to prevent the gastric tube being sucked against the mucosa. This ensured that the gastric contents were recovered as completely as possible. The collection of specimens was under constant personal supervision. Twelve specimens, each for a 15-minute period, were obtained from the gastric tube. Duodenal juice was collected in individual 15-minute periods during the acid infusion and for 15 minutes thereafter: the remaining duodenal specimens were bulked to form two larger collections, one for the interval before acid infusion and one for the last part of the test.

ESTIMATIONS The following estimations were made:

Gastric juice Volume; $p \mathrm{H}$ using a Cambridge $p \mathrm{H}$ meter; free and total acid by titration with N/100 sodium hydroxide solution, with Töpfer's reagent and phenolphthalein respectively as indicators; sodium and potassium by flame photometry; chloride by potentio- metric titration; and concentration of polyethylene glycol by colorimetry (Hyden, 1955).

Duodenal content Volume; $p \mathrm{H}$; free and total acid; concentration of polyethylene glycol.

From these measurements the total acid output, the $\mathrm{pH}$ attained in the duodenum, and the amount of reflux of duodenal contents could be calculated.

REFLUX The concentration of polyethylene glycol in gastric juice and in duodenal content was estimated and the amount of reflux calculated as in the following example:

Volume of gastric aspirate in $15 \mathrm{~min} . \quad .40 \mathrm{ml}$. Concentration of polyethylene glycol

in gastric aspirate $\ldots \ldots \ldots \ldots \ldots \ldots \ldots \ldots . . \ldots 07 \%$ Concentration of polyethylene glycol

in duodenal content $\ldots \ldots \ldots \ldots \ldots \ldots \ldots \ldots .28 \%$

Then reflux from the duodenum has been diluted $\frac{0.28}{0.007}$ times in the stomach, = 40 times, i.e., $1 \mathrm{ml}$. in $40 \mathrm{ml}$. gastric aspirate. Thus reflux was $1 \mathrm{ml}$. in 15 minutes.

VALIDITY OF TESTS The occurrence of over $5 \mathrm{ml}$. of reflux from the duodenum in $15 \mathrm{~min}$. led to the test being discarded.

\section{RESULTS}

GASTRIC SECRETORY RESPONSE TO CONSTANT INTRAVENOUS INFUSION OF HISTAMINE In 10 tests on nine patients with duodenal ulcer, the response of the stomach to intravenous histamine acid phosphate infused at a constant rate was observed for three hours. The mean values for acid output are shown in Fig. 2 from which it can be seen that the response was not diminished within the three hours. Individual tests are shown in Figure 3.

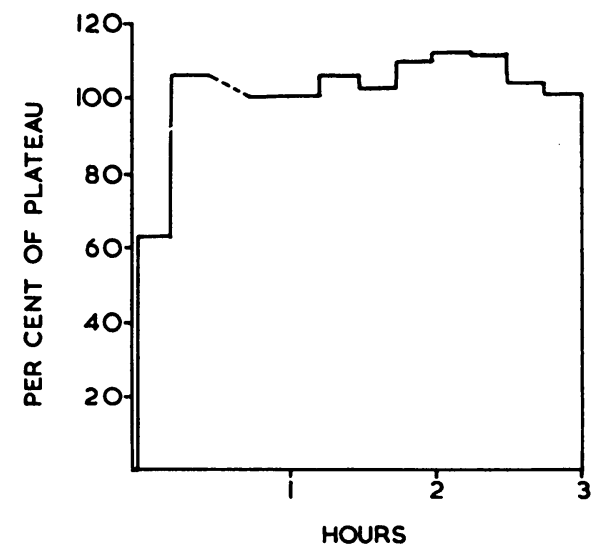

FIG. 2. Mean acid output in response to constant intravenous infusion of histamine in 10 tests on duodenal ulcer patients, expressed as a percentage of the plateau level. 


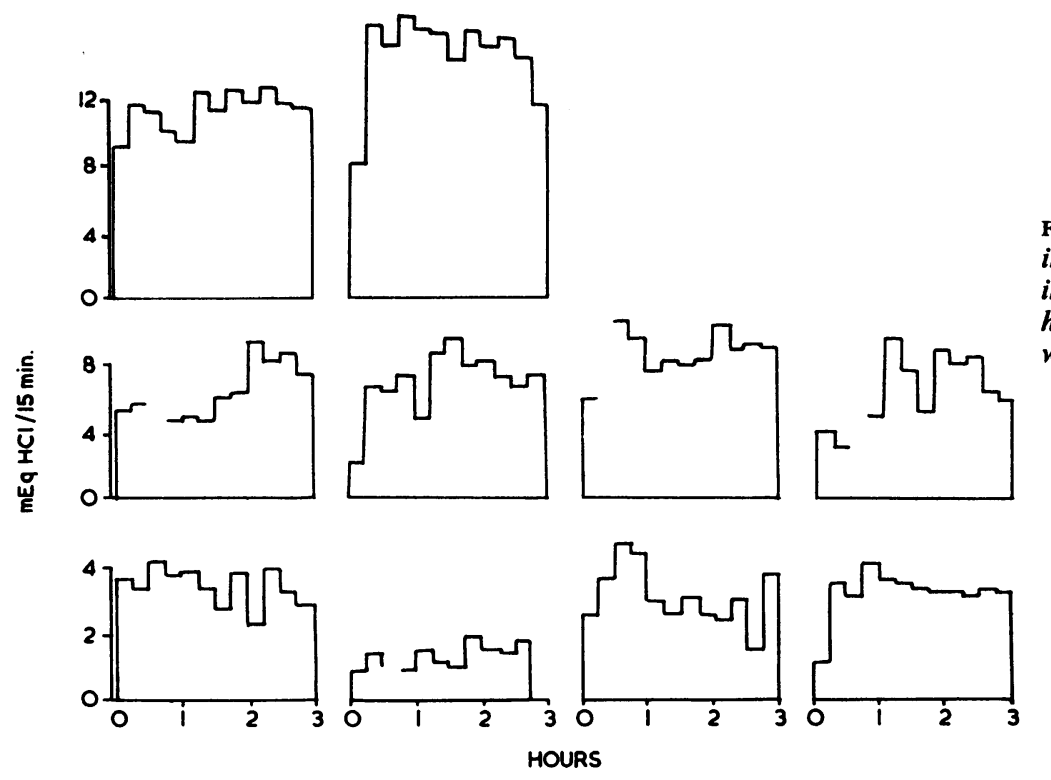

FIG. 3. Total acid output in response to constant intravenous infusion of histamine in 10 tests on patients with duodenal ulcer.
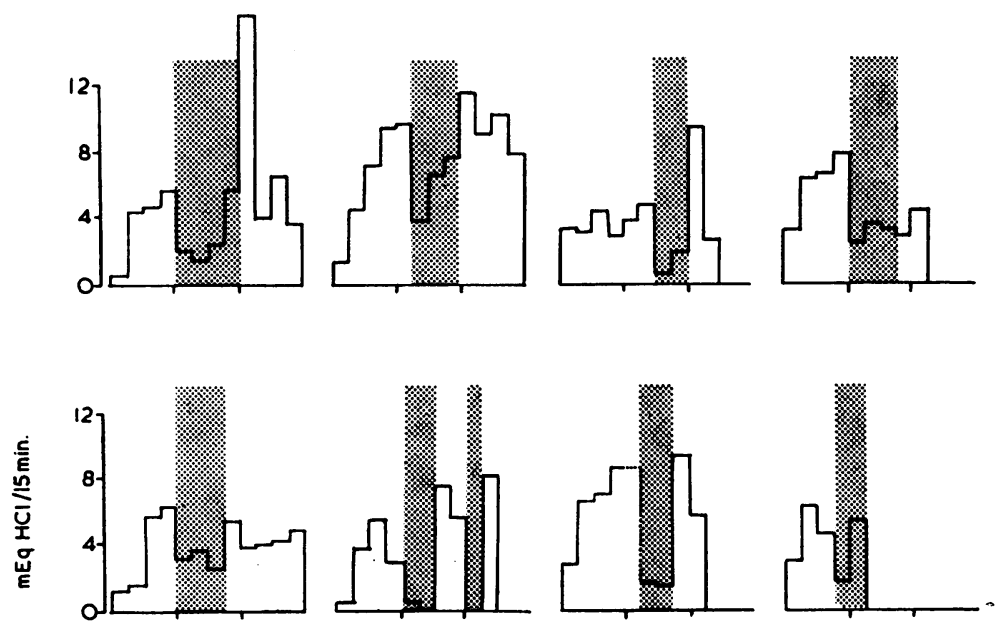

FIG. 4. The inhibitory effect of infusion of acid into the duodenum on the total acid output by the stomach in normal subjects in response to a constant intravenous infusion of histamine.

The shaded areas indicate the duration of infusion of acid into the duodenum.

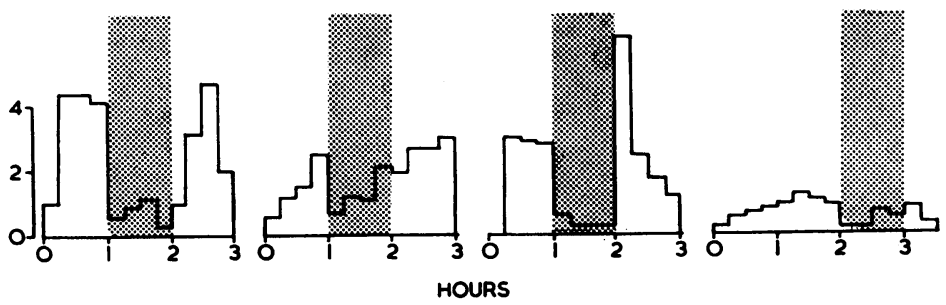


Dose-response relationship The response to the intravenous infusion of increasing doses of histamine acid phosphate in 31 duodenal ulcer patients and in 41 normal subjects has been compared with the response to the augmented histamine test (Kay, 1953) in 19 duodenal ulcer patients and in three normal subjects. In the first group of tests of inhibition in duodenal ulcer patients the dose of $0.4 \mu \mathrm{g}$. histamine acid phosphate per $\mathrm{kg}$. per min. gave a response similar to the augmented histamine test (Table I). In the second group of such tests doses of 0.025 to $0 \cdot 1 \mu \mathrm{g}$. histamine acid phosphate per $\mathrm{kg}$. per min. were used, eliciting secretion equivalent to less than two-thirds of the augmented histamine response.

\section{TABLE I}

RESPONSES OF PATIENTS WITH DUODENAL ULCER AND NORMAL SUBJECTS TO INCREASING DOSES OF HISTAMINE ACID PHOSPHATE INTRAVENOUSLY COMPARED

WITH THE MAXIMAL HISTAMINE RESPONSE IN THE AUGMENTED HISTAMINE TEST

\begin{tabular}{|c|c|c|c|}
\hline Subjects & $\begin{array}{l}\text { No. of } \\
\text { Cases }\end{array}$ & $\begin{array}{l}\text { Stimulus by Intravenous } \\
\text { Histamine Acid } \\
\text { Phosphatase (ug./kg./min.) }\end{array}$ & $\begin{array}{l}\text { Gastric } \\
\text { Secretion } \\
\text { (Total Acid } \\
\text { Output mEq./ } \\
\frac{1}{\mathrm{hr} . \text { ) }}\end{array}$ \\
\hline Duodenal ulcer & $\begin{array}{r}19 \\
5 \\
3 \\
6 \\
2 \\
8 \\
7\end{array}$ & $\begin{array}{l}\text { Augmented histamine test } \\
\begin{array}{ll}0.4 \\
0.25 \\
0.2 \\
0.1 \\
0.05 \\
0.025\end{array}\end{array}$ & $\begin{array}{c}11.12(100 \%) \\
11.09(99.72 \%) \\
9.17(82.47 \%) \\
8.125(73.09 \%) \\
6.07(54.59 \%) \\
5.30(47.66 \%) \\
3.246(29.35 \%)\end{array}$ \\
\hline Normals & $\begin{array}{r}3 \\
1 \\
1 \\
26 \\
8 \\
4 \\
1\end{array}$ & $\begin{array}{l}\text { Augmented histamine test } \\
\begin{array}{l}0.4 \\
0.3 \\
0.2 \\
0.1 \\
0.05 \\
0.025\end{array}\end{array}$ & $\begin{array}{l}6.92(100 \%)^{2} \\
3.71 \\
3.915 \\
6.292(90.93 \%) \\
6.01(86.86 \%) \\
3.98(57.51 \%) \\
1.46\end{array}$ \\
\hline $\begin{array}{l}{ }^{2} \text { Compare } 11.79( \\
{ }^{2} \text { Compare } 5.94(2\end{array}$ & 25 subje & s) $\}$ from Kay (1953) & \\
\hline
\end{tabular}

EFFECT OF ACID IN THE DUODENUM Of 47 tests, 20 were discarded on account of reflux of duodenal contents into the stomach. In the 27 tests accepted, reflux was less than $2 \mathrm{ml}$. per $15 \mathrm{~min}$. in 18, between 2 and $5 \mathrm{ml}$. in seven, and not accurately known in two.

Normal subjects Sixteen tests were valid. In 12, infusion of acid into the duodenum inhibited gastric secretion of acid. The tests are illustrated in Figure 4. In the remaining four tests, no significant inhibition occurred. In the 12 tests with inhibition the doses of histamine acid phosphate were $0.2 \mu \mathrm{g} . / \mathrm{kg} . / \mathrm{min}$. in eight, 0.1 in two, and 0.05 in two.

Volume was diminished in the tests showing inhibition. The concentration of acid did not change significantly. The total acid output was diminished significantly (Table II), the range being $27 \%$ to $95 \%$ with a mean inhibition of $57 \%$ (Fig. 5). Such inhibition was the more notable as in 10 of the 12 tests the stimulus produced a secretory rate that was nearly maximal (Table I). In one of the tests the subject's own gastric juice, aspirated during the first one and a half hours of the histamine infusion, was placed in the duodenum. A $75 \%$ inhibition of gastric acid secretion resulted.

The duodenal $p \mathrm{H}$ was 2.5 or less in 11 of the 12 tests showing inhibition and in two of the four tests showing no inhibition.

Patients with duodenal ulcer Six tests in group I $(0.4 \mu \mathrm{g}$. histamine acid phosphate per kg. per min.) were valid. In four of these no inhibition occurred: in the remaining two there may have been some inhibition in the first quarter of an hour (Fig. 6). The duodenal $p \mathrm{H}$ was less than 2 in two, and over 7 in four tests during the acid infusion.

Five tests in group II were valid $(0 \cdot 2 \mu \mathrm{g}$. histamine acid phosphate or less per $\mathrm{kg}$. per min.). Inhibition occurred in all five (Fig. 7), the mean inhibition of total acid output being $45 \%$. In this group, the duodenal $p \mathrm{H}$ attained levels under 2.5 in three tests, was over 6 in one, and in one no sample of duodenal juice could be obtained. Again the

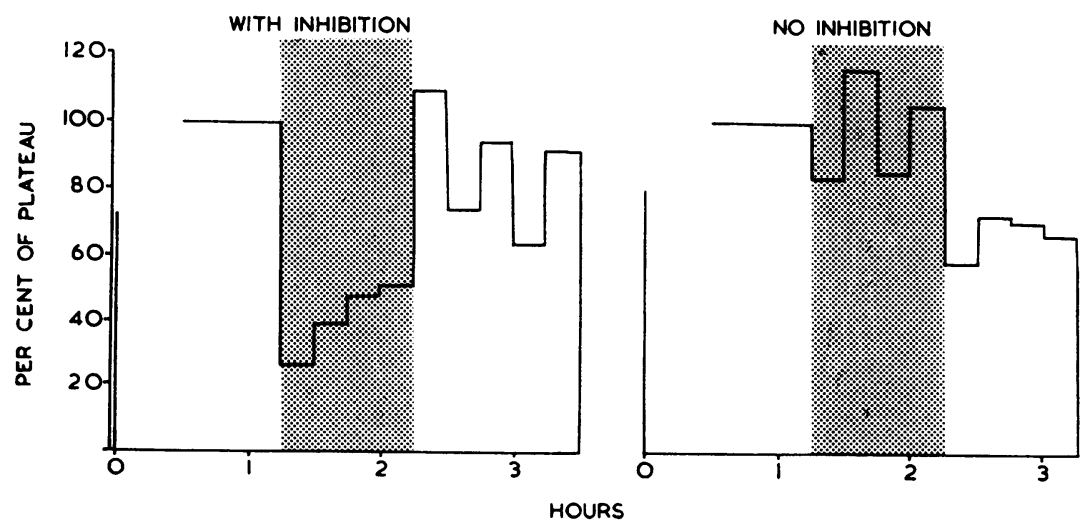

FIG. 5. Mean total acid output in response to a constant intravenous infusion of histamine showing the inhibitory effect of acid in the duodenum in 12 normal subjects and the lack of inhibition in four normal subjects. Acid output is expressed as a percentage of the plateau level. Shaded areas indicate duration of infusion of acid into the duodenum. 

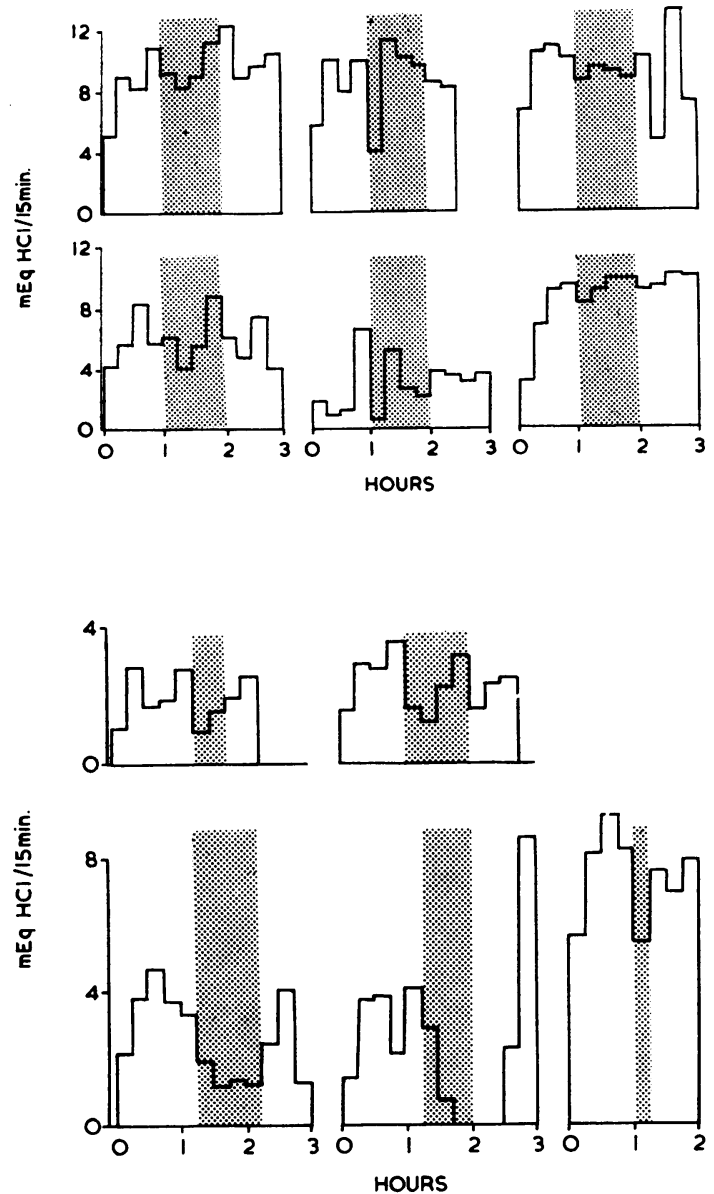

FIG. 6. Total acid output in patients with duodenal ulcer (group I) in response to a constant intravenous infusion of histamine giving maximal levels of secretion. In four tests, no inhibition is noted. In two, inhibition seen in the first 15 minutes was not maintained.

The shaded area indicates the duration of acid infusion into the duodenum.
FIG. 7. Total acid output in patients with duodenal ulcer (group II) in response to a constant intravenous infusion of histamine in submaximal dosage. Inhibition is seen in all five tests.

The shaded area indicates the duration of acid infusion into the duodenum.

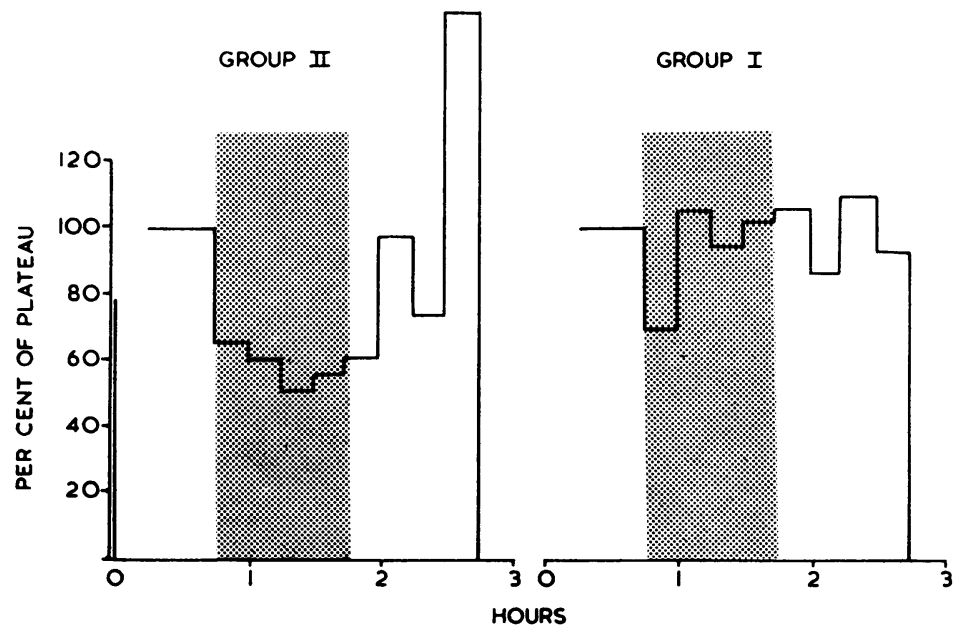

FiG. 8. Mean total acid output in patients with duodenal ulcer (groups I and $I I)$ in response to constant intravenous infusion of histamine, the shaded areas indicating the duration of acid infusion into the duodenum. Convincing inhibition of gastric acid secretion is seen at the lower levels of histamine stimulation (group II). 
TABLE II

EFFECT OF ACID IN DUODENUM

\begin{tabular}{|c|c|c|c|c|c|c|c|c|}
\hline \multirow[t]{3}{*}{ No. } & \multirow[t]{3}{*}{ Subject } & \multirow{3}{*}{ 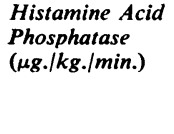 } & \multicolumn{2}{|c|}{ Duodenal $\mathrm{pH}$} & \multicolumn{4}{|c|}{ Total Acid Output (mEq./1 hr.) } \\
\hline & & & \multirow[t]{2}{*}{ Control } & \multirow[t]{2}{*}{ With Acid } & \multirow{2}{*}{$\begin{array}{l}\text { Control } \\
\text { (Plateau) }\end{array}$} & \multirow{2}{*}{$\begin{array}{l}\text { Acid in } \\
\text { Duodenum }\end{array}$} & \multicolumn{2}{|c|}{$\%$ Inhibition } \\
\hline & & & & & & & Mean & Range \\
\hline $\begin{array}{l}12 \\
4 \\
6 \\
\text { Group I }\end{array}$ & $\begin{array}{l}\text { Normal } \\
\text { Normal } \\
\text { Duodenal ulcer }\end{array}$ & $\begin{array}{l}0.05-0.2 \\
0.05-0.2 \\
0.4\end{array}$ & $\begin{array}{l}7-8 \\
7-8 \\
7-8\end{array}$ & $\begin{array}{l}<2.5 \text { in } 11 \\
<2.5 \text { in } 2 \\
<2.5 \text { in } 2\end{array}$ & $\begin{array}{l}5 \cdot 56 \\
6 \cdot 45 \\
8 \cdot 04\end{array}$ & $\begin{array}{l}2 \cdot 38 \\
6 \cdot 15 \\
7 \cdot 34\end{array}$ & $\begin{array}{r}57 \\
5 \\
9\end{array}$ & $\begin{array}{l}27-95 \\
15 \text { to }-23 \\
1-15\end{array}$ \\
\hline $\begin{array}{l}5 \\
\text { Group II }\end{array}$ & Duodenal ulcer & $0.025-0.2$ & $7-8$ & $<2.5$ in 3 & $4 \cdot 38$ & $2 \cdot 41$ & 45 & $36-67$ \\
\hline
\end{tabular}

volume of gastric juice was diminished and concentration of acid was not significantly changed.

The average results for both groups are shown in Fig. 8 and in Table II.

RAPIDITY OF ONSET The change in rate of flow along the suction tube from the stomach was obvious to the observer within two to five minutes of beginning the intraduodenal infusion of acid. In two cases collection of the gastric samples in fiveminute periods after the acid was given into the duodenum confirmed this early onset of inhibition.

DURATION OF INHIBITION Though there was no uniformity of pattern, in six of the 12 tests on normal subjects inhibition was maximal in the first 15 minutes. Overall, inhibition tended to decrease with the passage of time.

CORRELATION WITH DOSE OF HISTAMINE OR WITH SECRETORY LEVEL The degree of inhibition produced by infusion of acid into the duodenum did not vary directly with either the dose of histamine or with the acid output of the stomach, although a tendency to do so was apparent when comparing groups I and II of duodenal ulcer patients (Table III). Such a relationship might be clearly defined were it possible to do repeated tests on the same subject.

PAIN DURING ACID INFUSION The patients with duodenal ulcer all had some pain, usually their typical ulcer pain, at some time during the infusion

\section{TABLE III}

CORRELATION OF DOSE OF HISTAMINE OR SECRETORY LEVEL WITH DEGREE OF INHIBITION

\begin{tabular}{|c|c|c|c|}
\hline Subject & 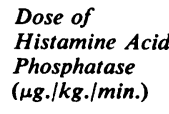 & $\begin{array}{l}\text { Total Acid } \\
\text { Output } \\
\text { (mEq./ } \mathbf{h r} \text { hr. } \\
\text { plateau })\end{array}$ & $\begin{array}{l}\text { Degree of } \\
\text { Inhibition } \\
(\%<\text { plateau })\end{array}$ \\
\hline Normal & $\begin{array}{l}0.05 \\
0.05 \\
0 \cdot 1 \\
0.1 \\
0.2 \\
0.2 \\
0.2 \\
0.2 \\
0.2 \\
0.2 \\
0.2 \\
0.2\end{array}$ & $\begin{array}{l}0.90 \\
3.08 \\
3.99 \\
7.10 \\
2.85 \\
4 \cdot 15 \\
4.40 \\
3.35 \\
5.50 \\
5.98 \\
7.23 \\
9.75\end{array}$ & $\begin{array}{l}54 \\
30 \\
73 \\
75 \\
89 \\
95 \\
83 \\
65 \\
34 \\
42 \\
60 \\
60\end{array}$ \\
\hline $\begin{array}{l}\text { Duodenal ulcer } \\
\text { (Group I) }\end{array}$ & $\begin{array}{c}\text { Mean of } 6 \\
0.4\end{array}$ & 8.04 & 9 \\
\hline $\begin{array}{l}\text { Duodenal ulcer } \\
\text { (Group II) }\end{array}$ & $\begin{array}{l}0.025 \\
0.025 \\
0.05 \\
0.10 \\
0.20\end{array}$ & $\begin{array}{l}2 \cdot 44 \\
3.97 \\
8.92 \\
3 \cdot 27 \\
3 \cdot 30\end{array}$ & $\begin{array}{l}57 \\
67 \\
37 \\
40 \\
36\end{array}$ \\
\hline
\end{tabular}

of acid into the duodenum. In two of the normal subjects pain was felt and one of these had nausea.

EFFECT OF SALINE IN THE DUODENUM The infusion of $0.9 \%$ saline into the duodenum in normal subjects and patients with duodenal ulcer failed to influence gastric acid secretion in response to constant intravenous infusion of histamine whether reflux from the duodenum was slight or obvious (Table IV).

TABLE IV

EFFECT OF SALINE IN DUODENUM

\begin{tabular}{|c|c|c|c|c|c|c|c|c|c|}
\hline \multirow[t]{2}{*}{ Reflux } & \multirow{2}{*}{\multicolumn{2}{|c|}{ No. of Subjects }} & \multirow{2}{*}{$\begin{array}{l}\text { Histamine Acid } \\
\text { Phosphatase } \\
\text { (ug./kg./min.) }\end{array}$} & \multicolumn{2}{|c|}{ Duodenal $\mathrm{p} H$} & \multirow{2}{*}{$\begin{array}{l}\text { Mean Reflux } \\
(m l .1+h r .)\end{array}$} & \multicolumn{3}{|c|}{ Total Acid Output (mEq./1 hr.) } \\
\hline & & & & Control & $\begin{array}{l}\text { With } \\
\text { Saline }\end{array}$ & & Control & $\begin{array}{l}\text { Saline in } \\
\text { Duodenum }\end{array}$ & $\begin{array}{l}\text { Percentage } \\
\text { of Control }\end{array}$ \\
\hline Slight & 11 & $\begin{array}{l}7 \text { normal } \\
4 \text { duodenal ulcer }\end{array}$ & $0.025-0.2$ & $7 \cdot 18$ & 6.97 & $2 \cdot 3$ & $6 \cdot 32$ & $6 \cdot 16$ & 97.47 \\
\hline Obvious & 8 & $\begin{array}{l}2 \text { normal } \\
6 \text { duodenal ulcer }\end{array}$ & $0.025-0.4$ & 6.99 & $6 \cdot 40$ & $26 \cdot 0$ & $5 \cdot 34$ & $5 \cdot 1$ & $95 \cdot 52$ \\
\hline
\end{tabular}




\section{DISCUSSION}

STimulus Histamine was chosen to evoke a constant response which could be maintained for three hours, as the control studies confirmed. While histamine may or may not be a physiological stimulus it has the advantage of being reliable.

When little or no inhibition was observed in the group I tests on duodenal ulcer, the dose of histamine was reduced in group II because it is well established that possible inhibitory mechanisms are best studied against a constant submaximal stimulus. The degree of inhibition of gastric secretion in response to acid in the duodenum in dogs has been shown to be inversely proportional to the secretory rate (Code, Blackburn, Livermore, and Ratke, 1949).

INHIBITION Hydrochloric acid N/10 was used as it has been the reference substance in assessing acid inhibition in the past and provided as severely acid conditions as the duodenum might experience. The large volume was used because a high proportion was immediately sucked out of the duodenum again. The $p \mathrm{H}$ levels in the duodenum were on average lower in those showing inhibition than in those who did not. This fits with the observation of Pincus et al. in 1942 that in dogs acid secretion was inhibited only if the intraduodenal $p \mathrm{H}$ was lowered to 2.5 or less. The work of Atkinson and Henley (1955) and of Berk, Rehfuss, and Thomas (1942) suggests that such low $p \mathrm{H}$ levels are indeed found in the proximal duodenum of man after a meal. From recordings made by a glass electrode carefully positioned in the duodenal bulb of patients with active duodenal ulcer, Rovelstad and Maher (1962) were able to state that 'after meals, the contents of the duodenal bulb may have a $p \mathrm{H}$ as low as $1.5 \ldots$ In three of four of their patients, the $p \mathrm{H}$ of the duodenal bulb fell to under 3.5 after a bland meal and a similar fall was noted in one normal man tested. The acid did have the advantage of delaying gastric emptying (Hunt, 1959) and so assisted in preventing loss of gastric juice through the pylorus. Studies with graded concentrations of hydrochloric acid would be of interest.

PERFUSION SYSTEM The continuous removal of duodenal contents during the infusion of acid had several advantages. It brought the acid into contact with the proximal part of the duodenum; it prevented distension of the duodenum, while the suction holes near the pylorus minimized reflux into the stomach; it produced samples of duodenal content on which $p \mathrm{H}$ and polyethylene glycol concentration could be measured.

The avoidance of reflux was especially important as any acid coming in contact with the antrum might vitiate the test as one specifically of duodenal inhibition. However, it is likely that the antrum was already maximally inhibited in these tests when the intragastric $p \mathrm{H}$ was about unity. The following observations tend to corroborate this point. First, when reflux did occur no additional inhibition which could have been antral in origin was noted. Secondly, in tests on three normal subjects the addition of $\mathrm{N} / 10$ hydrochloric acid into the antrum during an intravenous histamine infusion caused no inhibition. Even with these safeguards, we have excluded tests in which reflux of duodenal content was over $5 \mathrm{ml}$. per 15 minutes.

DISADVANTAGES OF METHOD The exact position of the duodenal tube could only be verified at the beginning and end of the test but usually with careful positioning it did not shift. The main drawback is the technical complexity of the test with the high rejection rate due to reflux. The impossibility of having clearly separated areas of duodenum into which to put the acid was inherent in any study on man. A segment of the duodenum could have been isolated between balloons on a triple-lumen tube, but it was felt that the distension required to produce a water-tight fit could in itself stimulate the duodenum.

RESULTS The demonstration of significant inhibition of gastric secretion in 12 of 16 normal subjects in response to infusion of acid into the duodenum confirms previous work in man (Griffiths, 1936; Shay et al., 1942). The lack of significant inhibition in three of the four remaining subjects might be explained by the following: failure to acidify the duodenum in two subjects; in another subject at the completion of the test the tip of the duodenal tube was in the distal third part of the duodenum. It may be that the inhibitory response can only be elicited from the proximal duodenum, as in the dog (Thompson, 1962). No defect could be found in the test on the fourth member of this group. It can only be postulated that this lack of inhibition is a normal variant or that his inhibitory mechanism is defective and he may be a candidate for later duodenal ulceration.

Pain was felt by all duodenal ulcer patients during the infusion of acid into the duodenum. That this pain did not have an inhibitory effect was seen by the lack of inhibition in group I of the duodenal ulcer patients. This might be said of the normal subjects but at the most in only two could pain have conceivably contributed to the inhibition of gastric secretion.

The lack of inhibition in group I of the patients 
with duodenal ulcer was in accord with the findings of Shay et al. (1942), who attributed hypersecretion and nocturnal acid secretion to a defective duodenal inhibitory mechanism. Closer examination of their data shows that they depended largely on the concentration of acid to assess inhibition. As we have shown in the normal subjects, even when inhibition was present the acid concentration may not alter significantly. Thus, there might have been some inhibition which escaped detection by these workers. In group II of the patients with duodenal ulcer a submaximal stimulus was used to elicit gastric secretion and significant inhibition was observed. This demonstrated that no qualitative difference existed between the normal subjects and the duodenal ulcer patients. However, the amount of inhibition tended to be less in the duodenal ulcer patients, $45 \%$ compared with $57 \%$ in the normal subjects, though the difference is not statistically significant with the small numbers of the present study. This lesser degree of inhibition was produced against lower secretory levels. The quantitative difference might be an aetiological factor in the pathogenesis of duodenal ulcer, but equally well could be due to alteration in function of the duodenum as a result of the scarring of the peptic ulceration.

We thank Professor J. C. Goligher for his encouragement and criticism during this study. We are greatly indebted to the normal volunteers and to the staff of the Radiology Department of Leeds General Infimary for their assistance.

\section{REFERENCES}

Andersson, S. (1960a). Inhibitory effects of hydrochloric acid in antrum and duodenum on gastric secretory responses to test meal in Pavlov and Heidenhain pouch dogs. Acta physiol. scand., 49, $231-241$.

- $(1960 \mathrm{~b})$. Inhibitory effects of hydrochloric acid in antrum and duodenum on gastric secretory responses to insulin hypoglycemia in Pavlov pouch dogs. Ibid., 50, 23-31.

- - and Uvnäs, B. (1961). Inhibition of postprandial gastric secretion in Pavlov pouches by instillation of hydrochloric acid into the duodenal bulb. Gastroenterology, 41, 486-490.

Atkinson, M., and Henley, K. S. (1955). Levels of intragastric and intraduodenal acidity. Clin. Sci., 14, 1-14.
Berk, J. E., Rehfuss, N. E., and Thomas, J. E. (1942). The acidity of the "ulcer-bearing area" of the duodenum in normal persons. Amer. J. dig. Dis., 9, 276-281.

Code, C. F., Blackburn, C. M., Livermore, G. R. Jr., and Ratke, H. V. (1949). A method for the quantitative determination of gastric secretory inhibition. Gastroenterology, 13, 573-588.

the regulatory effect of acid in the ducdenum on gastric secretion of acid. J. Physiol. (Lond.), 130, 233-252.

Day, J. J., and Webster, D. R. (1935). The autoregulation of the gastric secretion. Amer. J. dig. Dis., 2, 527-531.

Gillespie, I. E. (1959). Influence of antral pH on gastric acid secretion in man. Gastroenterology, 37, 164-168.

Griffiths, W. J. (1936). The duodenum and the automatic control of gastric acidity. J. Physiol. (Lond.), 87, 34-40.

Hunt, J. N. (1959). Gastric emptying and secretion in man. Physiol. Rev., 39, 491-533.

Hyden, S. (1955). A turbidimetric method for the determination of higher polyethylene glycols in biological materials. Lantbr. Högsk. Ann., 22, 139-145.

Ivy, A. C., and Mcllvain, G. B. (1923). The excitation of gastric secretion by application of substances to the duodenal and jejunal mucosa. Amer. J. Physiol., 67, 124-140.

Jones, T. W., and Harkins, H. N. (1959). The mechanism of inhibition of gastric acid secretion by the duodenum. Gastroenterology, 37, 81-86.

Kay, A. W. (1953). Effect of large doses of histamine on gastric secretion of $\mathrm{HCl}$ : an augmented histamine test. Brit. med. J., 2, 77-80.

Longhi, E. H., Greenlee, H. B., Bravo, J. L., Guerrero, J. D., and Dragstedt, L. R. (1957). Question of an inhibitory hormone from the gastric antrum. Amer. J. Physiol., 191, 64-70.

Pincus, I. J., Thomas, J. E., and Rehfuss, M. E. (1942). A study of gastric secretion as influenced by changes in duodenal activity. Proc. Soc. exp. Biol. (N.Y.), 51, 367-368.

Rovelstad, R. A., and Maher, F. T. (1962). Problems associated with assessment of the effects of diet, antacids, and anticholinergic agents on gastric and duodenal acidity, as measured by the glass electrode in situ. Gastroenterology, 42, 588-594.

Shapira, D., and State, D. (1961). The role of the antrum in intragastric acid inhibition. Ibid., 41, 16-23.

Shay, H., Gershon-Cohen, J., and Fels, S. S. (1942). A self regulatory duodenal mechanism for gastric acid control and an explanation for the pathologic gastric physiology in uncomplicated duodenal ulcer. Amer. J. dig. Dis., 9, 124-128.

Sokolov, A. P. (1904). Analysis of the secretory work of the stomach in the dog. [Thesis in Russian.] Vaǐsberg \& Gershunim, St. Petersburg. Quoted by Babkin, B. P. (1950). Secretory mechanism of the digestive glands, p. 462. Hoeber, New York.

Stevens, R. E., Segal, H. L., and Scott, W. J. M. (1939). The effect upon gastric secretion of introducing dilute hydrochloric acid into the duodenum. Amer. J. dig. Dis., 6, 706-711.

Thompson, J. C. (1962). The inhibition of gastric secretion by the duodenum and by the gastric antrum. A review. J. surg. Res., 2, 181-196.

Uvnäs, B., Andersson, S., Elwin, C. E., and Malm, A. (1956). The influence of exclusion of the antrum-duodenum passage on the $\mathrm{HCl}$ secretion in Pavlov pouch dogs. Gastroenterology, 30, 790-803.

Woodward, E. R., Lyon, E. S., Landor, J., and Dragstedt, L. R. (1954). The physiology of the gastric antrum: experimental studies on isolated antrum pouches in dogs. Ibid., 27, 766-785. 